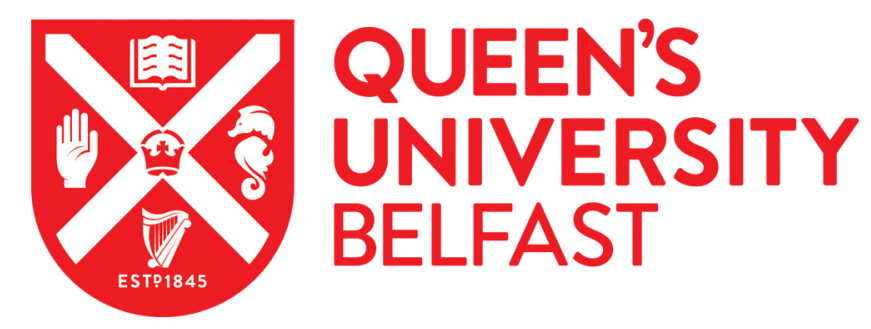

\title{
Adoption of farm-based irrigation water-saving techniques in the Guanzhong Plain, China
}

Tang, J., Folmer, H., \& Xue, J. (2016). Adoption of farm-based irrigation water-saving techniques in the Guanzhong Plain, China. Agricultural Economics , 47(4), 445-455. https://doi.org/10.1111/agec.12243

Published in:

Agricultural Economics

Document Version:

Peer reviewed version

Queen's University Belfast - Research Portal:

Link to publication record in Queen's University Belfast Research Portal

Publisher rights

Copyright 2016 Wiley.

This work is made available online in accordance with the publisher's policies. Please refer to any applicable terms of use of the publisher.

\section{General rights}

Copyright for the publications made accessible via the Queen's University Belfast Research Portal is retained by the author(s) and / or other copyright owners and it is a condition of accessing these publications that users recognise and abide by the legal requirements associated with these rights.

Take down policy

The Research Portal is Queen's institutional repository that provides access to Queen's research output. Every effort has been made to ensure that content in the Research Portal does not infringe any person's rights, or applicable UK laws. If you discover content in the Research Portal that you believe breaches copyright or violates any law, please contact openaccess@qub.ac.uk. 


\title{
Adoption of farm-based irrigation water-saving techniques in the Guanzhong Plain, China
}

\author{
Jianjun Tang ${ }^{a^{*}}$, Henk Folmer ${ }^{b, c}$, Jianhong Xue ${ }^{b}$
}

${ }^{\text {a }}$ Centre for Public Health / Gibson Institute for Land, Food and Environment, Queen's University Belfast, United Kingdom

${ }^{\mathrm{b}}$ Department of Agricultural Economics, College of Economics and Management, Northwest A\&F University, Yangling, Shaanxi, China, 712100

${ }^{\mathrm{c}}$ Department of Economic Geography, Faculty of Spatial Sciences, University of Groningen, Landleven 1, 9747 AD Groningen, The Netherlands

* Corresponding author. Tel.: +44 (028)90978955

Email addresses: j.tang@qub.ac.uk (J.Tang), h.folmer@rug.nl (H. Folmer),xuej@nwsuaf.edu.cn (J. Xue) 


\title{
Adoption of farm-based irrigation water-saving techniques in the Guanzhong Plain, China
}

\begin{abstract}
This paper analyses adoption of farm-based irrigation water saving techniques, based on a cross-sectional data set of 357 farmers in the Guanzhong Plain, China. Approximately 83\% of the farmers use at least one farm-based water-saving technique. However, the traditional, inefficient techniques border and furrow irrigation are still prevalent whereas the use of advanced, more efficient techniques is still rather rare. We develop and estimate an adoption model consisting of two stages: awareness of water scarcity and intensity of adoption. We find that awareness of water scarcity and financial status enhance adoption of more advanced techniques while access to better communitybased irrigation infrastructure discourages it. We furthermore find both community-based irrigation infrastructure and farm-based irrigation water-saving techniques have mitigating effects on production risk. From the results it follows that adoption can be stimulated via financial support and via extension aimed at enhancing awareness of water scarcity.
\end{abstract}

\section{JEL classification: D81 Q12 Q15 Q55}

Keywords: Water-saving techniques; Adoption; Social network; Production risk; Awareness of water scarcity; SEM; Non-parametric estimation; Extension 


\section{Introduction}

North China, which accounts for approximately 64\% of its arable land, is China's main food production area (Khan et al., 2009). However, the region has experienced severe water scarcity problems which are threatening the region's and China's agricultural sustainability with worldwide ramifications (Tang et al., 2013a). The annual water availability of $750 \mathrm{~m}^{3}$ per capita is far below the threshold of $1000 \mathrm{~m}^{3}$ for 'water scarcity'. ${ }^{1}$ In addition, because of the rapid advance of urbanization and industrialization, the agricultural sector is increasingly facing competition for water from industries and households which have greater marginal returns to water. In recent years, the risk of droughts in north-western China has been worsening because of climate change (Piao et al., 2010) and water pollution (MWR, 2012) which have further raised potential vulnerability of agricultural production. Meanwhile, groundwater extraction has led to a decline of the groundwater table, making underground water supply less reliable (Wang et al., 2007) and raising uncertainty about future water supply even further.

To supplement limited rainfall, irrigation is widely used to maintain food production at its current level. Approximately 50\% of the arable land is irrigated to produce $75 \%$ of the North's agricultural output (Tang et al., 2013a). Irrigation consumes 70\% of total water withdrawal in the Northwest (MWR, 2011). However, efficiency is very low (Tang et al., 2015). Therefore, increasing irrigation water use efficiency is crucial to reduce water shortage problems, particularly in the short and medium term. A major instrument to achieve this objective is adoption of efficient, i.e. water-saving, irrigation techniques. ${ }^{2}$

\footnotetext{
${ }^{1}$ Following UNDP, UNEP, World Bank and the World Resources Institute, a region is "water stressed", if annual water availability per capita is between 1,000 and $2,000 \mathrm{~m}^{3} /$ person. A region is "water scarce", if availability is below 1,000 m³/person (Shalizi 2006).

${ }^{3}$ For other solutions, e.g. irrigation management reform, see Tang et al. (2013a).
} 
Lohmar et al. (2003) observes that the adoption of efficient irrigation techniques in China remained low, although the Chinese government had strongly encouraged irrigation water saving. The traditional farm-based techniques border and furrow irrigation, are still prevalent, while modern techniques, like fertigation, the use of drought resistant varieties, and efficient community-based techniques, like drip irrigation and underground pipelines, are rare (Blanke et al., 2007).

The conventional factors supposed to affect adoption of agricultural techniques include farm and farmer characteristics, availability of credit, information and labor availability (see Feder et al. (1985) for a review). These factors have also been analyzed in relation to the adoption of irrigation techniques (Zhou et al., 2008; Abdulai et al. 2011; among others). In addition, production risk has been found to be an important determinant of adoption of agricultural techniques in general (Feder et al., 1985; Foster and Rosenzweig, 2010; Liu, 2013; among others). However, despite the evidence, production risk is frequently ignored in agricultural adoption studies in developing countries like China, because of measurement problems (Liu and Huang, 2013; Just et al., 2010).

The same applies to the broader notion of awareness of water scarcity (Tang et al., 2013b). According to Ajzen's (1985) Theory of Planned Behavior, awareness is a precursor to a decision to take actions. From this notion and following Scolobig et al. (2012) and Wachinger et al. (2013), we conceptualize awareness of water scarcity as the predisposition that, if strong enough, will induce a farmer to adopt water-saving irrigation techniques to hedge against production risk, i.e. smaller than optimal production outcome, due to unpredictable water shortage. ${ }^{3}$ The impact of awareness on adoption has been empirically confirmed. For instance, farmers' awareness of soil erosion has been frequently found to positively influence their adoption of soil conservation practices

\footnotetext{
${ }^{3}$ Note that since it is assumed to hedge against production risk, adoption is a regressor in the production risk model (see Section 2.3).
} 
(Shiferaw and Holden 1998; Semgalawe and Folmer 2000; Knowler and Bradshaw, 2007). Awareness has also been found to stimulate adaptation measures against extreme weather by coffee growers in Central America (Tucker et al., 2010) and against climate change by farmers in the Nile basin of Ethiopia (Deressa et al., 2011). Despite the evidence, few studies have taken awareness of water scarcity as a prerequisite to adopting water-saving techniques. An exception is Habiba et al. (2012) who, based on a dataset of 718 Bangladesh farmers, found that farmers' awareness of draught risk improved their adaptation practices. To the best of our knowledge, no studies have yet investigated the influences of farmers' awareness of water scarcity on adoption of water-saving techniques in China.

The need to consider awareness of water scarcity in adoption studies of agricultural techniques - including irrigation techniques - relating to northern China has increased because precipitation has begun to vary progressively across years because of climate change. Consequently, farmers are facing more frequent, and larger, unexpected hazards of extreme weather (e.g. extremely low precipitation). Hence, a farmer who is more aware of water scarcity is expected to be more inclined to adopt water-saving techniques to hedge against weather-related production risk ${ }^{4}$.

The main objective of this paper is to analyze adoption of farm-based irrigation techniques in the Guanzhong Plain, Shaanxi Province, China. In addition to the conventional determinants, notably farm characteristics, demographic and socioeconomic factors, awareness of water scarcity will also be considered. In addition, we analyze the impacts of adoption on production risk.

\footnotetext{
${ }^{4}$ Another way to hedge against weather-related production risk is changing the production portfolio. However, perception of water availability in the study area has not yet reached a state that farmers have started changing their portfolios. The cropping pattern (wheat rotated with corn) is quite stable (SPBS, 2012). Hence, the assumption of a constant production portfolio is justified.
} 
The paper is organized as follows. Section 2 presents the conceptual adoption framework including the production risk model. Section 3 describes data collection and presents descriptive statistics. In Section 4 the empirical results are discussed. Section 5 summarizes, concludes and presents policy recommendations.

\section{Conceptual model}

\subsection{Adoption model}

As introduction, we present a brief overview of irrigation techniques applied in the study area. For this purpose, we follow Wang et al. (2002) who pointed out that irrigation consists of the following three stages: (i) delivering water from reservoirs or groundwater pumping stations to the fields (earthen-lined canals; cement-lined canals; transportation pipelines); (ii) transferring water from fields to crop root (border irrigation; furrow irrigation; spray pipes); and (iii) uptake by the crop (mulching; drought-resistant varieties; fertigation). Each stage may incur water losses which can be reduced by stagespecific methods and techniques ${ }^{5}$.

A vast literature has focused on adoption of agricultural techniques. The models applied fall into two categories: static and dynamic (Marra et al., 2003). The former kind uses cross-sectional data and identifies the characteristics of adopters against non-adopters. Studies of this type include amongst others Green et al. (1996), Abdulai et al. (2005, 2011) and Zhou et al. (2008). The dynamic approach analyzes adoption of a specific technique over time, usually by means of a diffusion curve, estimated on the basis of panel data (Dinar and Yaron 1992; Carey and Zilberman 2002; among others). Due to data constraints, the static model is more widely used than the dynamic model. However,

\footnotetext{
${ }^{5}$ See the online Supplemental Appendix S.1 for a detailed description of the various water-saving techniques. We do not discuss other water saving techniques, such as rainwater collection, intermittent irrigation, drip and sprinkler irrigation, which were not applied by the interviewees. Meanwhile, since $90 \%$ plots in the Plain is ploughed and levelled by means of tractors, plot levelling is also not discussed because it is not a characteristic that varies across the study area and thus does not affect adoption decisions.
} 
by its very nature, the static approach does not allow direct modelling of the dynamics of the adoption decision (Doss, 2006).

The present study is also based on cross-sectional data. However, we (partly) overcome its disadvantage by taking adoption as a sequential, multi-stage process, as suggested by among others Ervin and Ervin (1982), Semgalawe and Folmer (2000), Dimara and Skuras (2003), Bewket (2007) and De Graaff et al. (2010). The model suggested in these literatures is a three-stage model consisting of the following stages: (i) awareness of the problem; (ii) decision to adopt or not; and (iii) intensity of adoption. The decision to adopt can be conveniently captured by intensity of adoption with no adoption defined as intensity zero. Hence, we propose the following two-stage model: (1) awareness of water scarcity (WaterAwareness), and (2) intensity of adoption (AdoptIntensity). We present the conceptual adoption model in Figure 1.

[Figure 1 about here]

We now present definitions and measurements of the core variables in Figure 1. Before going into detail, note that we endogenize WaterAwareness since it depends upon various potential policy handles including perception of water scarcity, media exposure and connection to a social network. The awareness model is to provide insight into the impacts of these variables on WaterAwareness and thus indirectly on adoption.

We first point out the main features of the WaterAwareness sub-model. The discussion is based on Tang et al. (2013b) to which we refer for details. WaterAwareness is defined as a farmer's attention to, and concern about, water scarcity and its negative impacts on production. It is a latent variable or theoretical construct measured by the responses to the following three statements: (i) present availability of irrigation water is hindering 
agriculture production; (ii) I always worry about irrigation water shortage; (iii) saving irrigation water is important. Answers to each statement are recorded on a 5-point scale, ranging from “strongly disagree” to "strongly agree”.

The key explanatory variable in the WaterAwareness model is Perception, which we define as the recognition of the state of water availability. ${ }^{6}$ Like WaterAwareness, it is a latent variable and is measured by the following indicators which relate to the farmer's production area: Percep1 (knowledge of current water availability), Percep2 (knowledge of changes of water availability), Percep3 (knowledge of changes of water quality) and Percep4 (expectation of future water scarcity). Each indicator is measured on a 5-point scale ranging from "strongly disagree” to "strongly agree”. Tang et al. (2013b) shows that WaterAwareness is highly dependent on perception of water scarcity (Perception) and vice versa. To control for endogeneity of WaterAwareness, we apply a two-equation structural equation model (SEM), as in Tang et al. (2013b), to obtain predicted WaterAwareness as explanatory variable in the adoption model.

We now turn to the adoption sub-model. The dependent variable is AdoptIntensity which we measure as the level of the most efficient irrigation techniques adopted (Paxton et al., 2011). ${ }^{7}$ We distinguish four efficiency levels: zero, i.e. no adoption (flood irrigation), low (furrow and border irrigation), medium (mulching and spray pipes), and high (fertigation and drought-resistant varieties). AdoptIntensity takes the value 0 in the case of nonadoption (flood irrigation); 1 if a farmer has adopted at least one of the low-level techniques but no medium or advanced techniques; 2 if at least one of the medium-level techniques, but no high-level techniques, has been adopted; 3 if at least one of the high

\footnotetext{
${ }^{6}$ For a detailed discussion of the notion of perception and of the other explanatory variables in the Waterawareness model we refer to Tang et al. (2013b).

${ }^{7}$ Note that a farmer may adopt multiple techniques, e.g. furrow (low) and mulching (medium). The most efficient one adopted is used to define a farmer's AdoptIntensity.
} 
level techniques has been adopted. Descriptive statistics of AdoptIntensity are presented in Table 2.

We now discuss the explanatory variables of AdoptIntensity. From Section 1 it follows that (predicted) WaterAwareness as the precursor to a decision to take action (adoption) is a key explanatory variable. Regarding the other explanatory variables, we include: (i) regional canal characteristics including CommunityTechnique, i.e. irrigation infrastructure in the community (earthen-lined canals, cement-lined canals, and transportation pipelines) and WaterPrice; and (ii) the farmer characteristics Age, Education, Time, FinancialStatus, Network and Media.

The canal characteristics are constant for the farmers using the same canal, but vary across canals. CommunityTechnique takes the value 0 if the irrigation canal is earthenlined, and 1 if it is cement-lined or transportation pipelines. Its impact on adoption intensity is ambiguous. On the one hand, farmers might view connection to a cementlined canal or system of transportation pipelines as sufficient in terms of water saving which would dispel their incentives to adopt medium or high level farm-based techniques. On the other hand, farmers who are equipped with efficient community canals may want to intensify the water saving capacity of their canals by adopting intermediate or advanced techniques. WaterPrice is the volumetrically-based price a farmer pays for irrigation water. Prices of surface water are set by canal managers while underground water includes only pumping costs. We expect it to have a positive impact on adoption because it implies cost saving.

We now turn to the farmer characteristics. Age, measured in years, is expected to have a negative impact because older farmers have a shorter payback period of the investments than younger farmers. Education (years of schooling) has a positive expected sign because schooling improves a farmer's capacity to collect and process information on 
water-saving techniques. Time is working time spent on farming and is measured on a 5point scale: $1=0 \%-19 \%, 2=20 \%-39 \%, 3=40 \%-59 \%, 4=60 \%-79 \%, 5=80 \%-100 \%$. Its expected sign is negative since part-time farmers have fewer opportunities to take care of their farms. Moreover, they are less dependent on farming income than full-time farmers, reducing their incentives to invest in farming including acquisition of the more expensive medium and high level irrigation techniques (see e.g. Boncinelli et al., 2016). FinancialStatus is measured by the response to the question "I have enough money to invest in water-saving techniques" on a 5-point scale ranging from "strongly disagree” to "strongly agree". Since higher-level techniques are more expensive than lower-level techniques in terms of initial investment and annually recurrent financial outlays (see Supplemental Appendix S.1), we expect a positive impact. ${ }^{8}$ Network indicates a farmer's connection to his or her peers. It is measured by the following four indicators: (i) I often discuss water scarcity issues with other villagers (Network1); (ii) I am a member of a water users' association (WUA) (Network2); (iii) I have relatives or neighbors who are using water-saving techniques (Network3); (iv) I have relationships with the local government or irrigation managers (Network4). Network1 is measured on a 5-point scale ranging from "strongly disagree" to "strongly agree”. Network 2-4 are dichotomous variables taking the value 1 if "Yes", and 0 if "No". Network is the sum of Network1-4. We expect that the more a farmer is connected, the higher the adoption intensity because of more and better information about water scarcity and the various irrigation techniques. Media represents a farmer's access to medias which is measured by the following four questions: How many times a week do you: (i) watch TV or listen to the radio?; (ii) read newspapers or books?; (iii) surf the internet?; (iv) see slogans or propaganda on water saving? The four questions are measured on 5-point scales ranging from "never" to "more

\footnotetext{
${ }^{8}$ Possible endogeneity of this variable and its controlling are discussed in Section 4.
} 
than 7 times a week". The scores of the four questions are summed to form a respondent's total score on Media. As in the case of Network, we expect a positive impact. Experience is drought experience which is measured by the answer to the question "In the past, it was easy to get water when I irrigated my land.” again on a 5-point scale ranging from “strongly disagree” to "strongly agree”.

\subsection{Production risk}

As mentioned in the introduction, we also analyze the impact of adoption on reduction of production risk. Kumbhakar (2002) shows that the uncertainties on production and output price are two main sources of production risk. In this paper, we do not consider output price uncertainty because the prices for wheat and corn (the commodities considered in this paper) in China are stable and farmers are generally price takers. The main hypothesis investigated here is that adoption reduces production risk.

Production risk is obtained from production function (1), introduced by Just and Pope (1978) and developed by Kumbhakar (2002):

$Y=f(X, A I)+g(X, A I) \varepsilon$,

where $Y$ is output, $X$ a vector of inputs including labor, water, other inputs per mu, $A I$ is AdoptIntensity, i.e. the most efficient irrigation technique used, and $\varepsilon$ the error term. ${ }^{9}$ Following Kumbhakar and Tsionas (2010), we assume that $E(\varepsilon \mid X)=0$ and $E\left(\varepsilon^{2} \mid X\right)=$ 1. The production function is composed of two components: (i) $f(X, A I)$, the mean production function, irrespective of production risk; and (ii) $g(X, A I)$, the output risk function which gives the effect of each of the inputs and irrigation techniques on the variation of the mean production, i.e. production risk.

\footnotetext{
${ }^{9}$ Land is not explicitly included, since labor, water and other inputs are per $m u$ of land (15 mu=1 hectare).
} 
We assume fully rational farmers who maximize the following objective function (Kato et al., 2011):

$$
\mathrm{E}(\mathrm{U}(\pi))=\mathrm{E}\left[\mathrm{U}\left(p_{y} f(X, A I)+p_{y} g(X, A I) \varepsilon-\sum_{i=1}^{3} p_{i} x_{i}-\sum_{j=1}^{2} p_{j} A I_{j}\right)\right]
$$

where $E[U()$.$] is the von Neumann-Morgenstern (1947) expected utility function which is$ assumed to be continuous and differentiable, $\pi$ is profit, $p_{y}$ the price of yield, $p_{i}$ the price of input $x_{i}$ and $p_{j}$ a set of prices corresponding to the water-saving techniques $A I_{j}$ described in Section 2.1. The first-order conditions (FOC) of utility maximization with respect to water-saving techniques are:

$\mathrm{E}\left(\mathrm{U}^{\prime}(\pi)\right)\left\{p_{y} f_{j}(X, A I)+p_{y} g_{j}(X, A I) \varepsilon-p_{j}\right\}=0$

where $\mathrm{U}^{\prime}(\pi), f_{j}(X, A I)$, and $g_{j}(X, A I)$ are partial derivatives with respect to water-saving technique $A I_{j}$, respectively.

The mean production function $f(X, A I)$ and the risk function $g(X, A I)$ need to be estimated simultaneously which can be done parametrically or non-parametrically (Kumbhakar and Tsionas, 2009). We opt for the non-parametric approach because parametric estimation of the system frequently fails to converge or produces unstable estimates due to an ill-behaved system of first-order conditions (Kumbhakar and Tsionas, 2009, 2010; Czekaj and Henningsen, 2013). This approach involves regression of output $Y$ on $X$ and $A I$ to obtain predicted $\hat{f}(X, A I)$ and the residual $e=Y-\hat{f}(X, A I)$. For this purpose, Kumbhakar and Tsionas (2010) suggest to apply multivariate kernel regression. The variance $e^{2}$ is taken as production risk (PR). Note that a larger value of $e^{2}$ indicates higher production risk. The production risk function $g(X, A I)$ is estimated by regressing the absolute value of the residual $e$ on the same set $X$ and $A I$ as in the first step, again by multivariate kernel regression. 


\section{Data collection and descriptive statistics}

Data was collected through face-to-face interviews with a sample of 446 farmers from the Guanzhong Plain which is a typical water-stressed area in North China (for a description of the area see Supplemental Appendix S.2). The survey took place in October, 2011 when the corn harvest had been finished. The sampling scheme was a four-stage stratified random sampling. At the first stage, of the 100,000 irrigation districts scattered in the Guanzhong Plain, we selected the nine largest which cover $80 \%$ of the total irrigated area. At the second stage, 2 to 12 canals were randomly sampled per irrigation district, proportionally to the total number of canals in the districts. The canals irrigate one or more villages. At stage three, per canal one upstream and one downstream village were randomly selected. Finally, 5 to 7 farmers were randomly sampled per village. Nonirrigators were excluded, resulting in a sample of 357 farmers. ${ }^{10}$

The respondents were asked to provide information on crop-specific inputs and outputs for the entire crop season. Since no accurate devices were used in the area to gauge the exact volume of water extracted, this piece of information was inferred from the size of canal, the number and duration of each of the irrigation spells. Most of the farmers were able to report the duration of extraction (in hours) and the volume extracted per hour. For the small number of farmers who did not know their canal sizes, we used the information obtained from the other farmers who used the same canal.

Table 1 presents overall descriptive statistics of the variables included in the analysis (except AdoptIntensity which is displayed in Table 2). Output is measured in Yuan/mu; Labor in man-days/mu; Water in $\mathrm{m}^{3} / \mathrm{mu}$. Other inputs is the sum in Yuan/mu of all other inputs including seeds, fertilizers, pesticides, plastic sheeting and machinery.

\footnotetext{
10 There were 55 non-irrigators. The reasons for non-irrigation were: (i) rainfall considered sufficient ( $n=32)$; (ii) no irrigation infrastructure present $(n=25)$; (iii) water price considered excessively high $(n=17)$; (iv) irrigation considered not profitable $(n=5)$; (v) lack of labor $(n=2)$.
} 
[Table 1 about here]

Table 2 shows that, cement-lined canals are the most common among the three community-based techniques, but that a substantial proportion of farmers (41\%) are still served by earthen-lined canals. Transportation pipelines are also rare (4\%). Regarding farm-based techniques, the vast majority (82\%) still uses the traditional techniques furrow and border irrigation. Even more so, flood irrigation is still common and applied by $19 \%$. Finally, only $6 \%$ of the farmers use drought-resistant varieties and approximately $10 \%$ apply mulching or fertigation.

[Table 2 about here]

\section{Estimation results}

\subsection{WaterAwareness model}

Since the predicted WaterAwareness is inserted into the adoption model, we first estimate the WaterAwareness model. As in Tang et al. (2013b), it is estimated as a structural equation model (SEM), which consists of a measurement model of the latent variables WaterAwareness and Perception, and a two-equation structural model. The measurement model is presented in Table 3. It shows that Aware1 (availability of irrigation water is hindering agricultural production) and Aware2 (I always worry about irrigation water shortage) are reliable indicators $\left(\mathrm{R}^{2}>0.35\right)$ of WaterAwareness while Aware3 (saving irrigation water is important) has substantially lower reliability. Similar conclusions apply to measurement of Perception, with factor loadings for Percep1-4 being 0.842, 0.503, 0.283 and 0.457, respectively. All in all, WaterAwareness and Perception are well measured.

[Table 3 about here] 
Table 4 presents the structural model (see Supplemental Table S.1 for the total effects). The results are in line with the structural model in Tang et al. (2013b) to which we refer for a discussion of the Perception equation. From Table 4 we conclude that Perception, Network, Time and Age are the significant determinants of WaterAwareness. In line with expectations, Perception has a substantial positive impact on WaterAwareness. Network indicates that farmers who are more connected to peers, water users' associations, relatives, neighbors, or local opinion leaders, are more aware of water scarcity than those who are poorly connected. Apparently, one's network is an important source of information about water scarcity and awareness of it. We also find that the more time a farmer spends on farming, the larger their WaterAwareness. Age on the other hand has a negative effect. Apparently, older farmers are less aware of water shortage than their younger peers. Finally, Education and Media have the wrong sign, but are highly insignificant. Apparently, Education is not a prerequisite for awareness of water scarcity nor does Media play much of a role. Based on the SEM model, WaterAwareness for each farmer is predicted by factor score regression and is then used as an explanatory variable in the adoption model.

[Table 4 about here]

\subsection{AdoptIntensity model}

Before discussing the main results of the AdoptionIntensity model, one should note that there is a potential endogeneity problem with respect to FinancialStatus - defined as a farmer's self-assessment of financial constraints on investing in water-saving techniques and AdoptIntensity because both may be affected by omitted variables. Moreover, in addition to the impact of FinancialStatus on AdoptIntensity, there may also be a reverse 
effect. To control endogeneity, a bivariate ordered probit model (Sajaia, 2008) is estimated because both of the dependent variables (FinancialStatus and AdoptIntensity) are ordinal. All explanatory variables in the AdoptIntensity equation are used to predict FinancialStatus. In addition, we include Nmigrants - the number of household members who spend more than $60 \%$ of their time on off-farm activities in other provinces - in the FinancialStatus model. Nmigrants is a proper instrumental variable because it is highly, positively correlated with financial resources but not with adoption of water-saving techniques.

The FinancialStatus and AdoptIntensity equations (bivariate ordered probit model) are estimated simultaneously via a backward stepwise procedure using the Stata package bioprobit. That is, we start with the initial (i.e. the conceptual) model and delete insignificant variables one by one, starting with the one with the highest $p$-value. Variables with $p$-values less than 0.10 were retained. The model thus obtained is the final model.

The initial and final models are reported in Table 5 which shows that in the final model WaterAwareness, FinancialStatus and CommunityTechnique are significant. Table 6 presents the marginal effects of the main variables of interest, i.e. the average changes in the probabilities of adopting the water-saving techniques due to unit changes in these independent variables.

[Table 5 about here]

[Table 6 about here]

The significant negative marginal effect of WaterAwareness on AdoptIntensity=0 (-3.7\%) and the significant positive impacts on AdoptIntensity=2 (0.9\%) and AdoptIntensity=3 (3.7\%) indicate that farmers with higher awareness of water scarcity tend to stay away 
from flood irrigation and to adopt more advanced techniques, notably high-level ones. Cement-lined canals and transportation pipelines tend to encourage flood irrigation (AdoptIntensity=0: 6.9\%) and discourage adoption of medium and highly efficient farmbased techniques (AdoptIntensity=2: $-1.5 \%$ ) and (AdoptIntensity=3: $-4.8 \%$ ), respectively. Apparently, having access to the community-based techniques is viewed as sufficient water-saving strategy. The results for FinancialStatus indicate that farmers who perceive better financial resources tend to adopt medium (AdoptIntensity=2: 1.5\%) and highly efficient (AdoptIntensity=3: 6.5\%) farm-based techniques and to stay away from notably flooding (AdoptIntensity=0: $-5.9 \%$.

\subsection{Production risk model}

To obtain production risk, we estimated the mean production function and the risk function in (1) by means of nonparametric multivariate kernel regression using the add-on package "np" in the statistical software package $R$. To avoid possible negative marginal products, we imposed monotonicity constraints to the three inputs (Du et al. 2013). Table 7 presents the marginal effects of Labor, Water, Other inputs, CommunityTechnique and AdoptIntensity on the mean production function and risk function, respectively. It is shown that the marginal output effect of Labor (9.739) is substantially larger that of Water (0.056) and of Other inputs (0.304). The largest output effect, however, is obtained for CommunityTechnique. Compared to the base case earthen-lined canals, the marginal output effect of cement-lined canals and transportation pipelines is 43.765 (95\% CI: 40.727, 46.803). The marginal output effect of AdoptIntensity is 3.819 (95\% CI: 0.455, 7.183). Note that although the standard errors are large and the confidence intervals are wide, the impacts are positive. Similar high standard errors for marginal output effects are also reported in Kumbhakar and Tsionas (2009). Furthermore, from Figure 2a which presents the distributions of the marginal effects of the two techniques on output it 
follows that CommunityTechnique increases output for the vast majority of farmers (97\%). ${ }^{11}$ For AdoptIntensity this is the case for $48 \%$ only, but the mean effect is still positive (see Figure 2b).

From the above it follows that both CommunityTechnique and AdoptIntensity have positive output effects. However, investment in cement-lined canals or transportation pipelines has a larger impact than investment in efficient farm-based techniques. A possible explanation is that water shortage has not yet reached a level which seriously hampers output. Consequently, investment in community-based techniques suffices.

The second panel of Table 7 shows that Water (-0.007 (95\% CI: -0.013, -0.002)) slightly decreases production risk indicating that irrigation helps maintain a high yield and contributes to eliminating risk due to droughts. Similar results are reported in Groom et al. (2008). Labor (10.981 (95\% CI: 10.565, 11.398)) and Other inputs (0.127 (95\% CI: $0.112,0.143)$ ) on the other hand increase it. The explanation is that labor contributes to increased production in an already good setting and thus increases output incidentally rather than structurally which increases variability. This is in line with other studies, such as Serra et al. (2008) and Foudi and Erdlenbruch (2012). For Other inputs the increase in production risk probably derives from limited controllability. For instance, increased fertilization may be suboptimal, turn into over-fertilization and lead to crop failure if the actual (e.g. weather) conditions deviate from the predicted conditions. Similar results are reported by Picazo-Tadeo and Wall (2011) and Zhang et al. (2013). Both CommunityTechnique and AdoptIntensity decrease production risk, although the means differ: -5.404 (95\% CI: $-6.273,-4.534)$ and -3.263 (95\% CI: $-3.653,-2.874)$, respectively. ${ }^{12}$ These outcomes are confirmed by the distributions presented in Figure 3

\footnotetext{
${ }^{11}$ The distributions of the other inputs are available upon request from the first author.

${ }^{12}$ Note that the standard errors in the case of production risk are substantially smaller than in the previous case of output.
} 
which are skewed to the left. Particularly, cement-lined canals and transportation pipelines decrease production risk for $83 \%$ of the farmers (Figure 3a). Figure 3b shows that for farm-based techniques this proportion is slightly less: $81 \%$. The rationale is that efficient community-based and farm-based irrigation techniques reduce dependency on water and thus reduces production risk.

[Table 7 about here]

[Figure 2 about here]

[Figure 3 about here]

\section{Summary, conclusions and policy recommendations}

China has been facing rapidly increasing water shortage problems in the North which will have substantial impacts on food security, economic development and the environment, in the region, China, and even internationally via shocks in international grain markets. A major reason for water shortage in Northern China is inefficient use of irrigation water. This paper has investigated adoption of water-saving irrigation techniques, based on a sample of 357 farmers in the Guanzhong Plain. Adoption is modelled as a sequential process consisting of the two stages awareness of water scarcity and intensity of adoption. The main conclusions are the following.

First, the adoption rate of farm-based water-saving techniques is high. Approximately $80 \%$ of the farmers use at least one farm-based water-saving technique. However, traditional irrigation techniques such as furrow irrigation are still prevalent while the adoption rates of advanced techniques such as mulching, drought-resistant varieties and spray pipes are low.

Secondly, awareness of water scarcity is a major determinant of adoption, i.e. farmers who are more aware of water scarcity are more likely to adopt more efficient water- 
saving irrigation techniques than those who are less aware. Hence, improving awareness is a major policy handle to promote adoption of efficient irrigation techniques.

Thirdly, adoption has a mitigating effect on production risk. It thus is a substitute for the limited alternatives in China to hedge against production risk. For instance, crop insurance is still rare in China. The importance of adoption as hedging mechanism against production risk is expected to increase along with the more frequent and more serious droughts in the region because of climate change. Note that this is an important piece of information for inter alia promotion campaigns to stimulate adoption.

Fourthly, social networks positively affect awareness of water scarcity. Apparently, farmers tend to have confidence in the opinions on water scarcity and water-saving techniques of their peers, water-user associations, neighbors and relatives. Therefore, extension agencies ought to target social networks to promote irrigation water saving. The agencies should particularly focus on opinion leaders with a positive attitude towards adoption of water saving techniques in a bid to make their experiences and opinions spillover to other farmers.

Fifthly, cement-lined canals and transportation pipelines, and the medium and highly efficient farm-based techniques have positive impacts on output and negative effects on production risk. However, investments in both types of techniques, especially the community-based, imply substantial financial outlays that are beyond the financial means of most farmers in the Guanzhong Plain. Particularly, 74\% of the farmers reported to have insufficient financial means to invest in medium or highly efficient water-saving techniques. Furthermore, the presence of cement-lined canals or transportation pipelines reduces farmers' incentives to invest in medium and highly efficient farm-based techniques. Since the possibilities for farmers to obtain credit on feasible terms are 
limited ( $\mathrm{Li}$ et al. 2011), an important policy handle is improvement of accessibility to credit for investment in water-saving techniques.

Efficient use of irrigation water is a prerequisite for sustainable agriculture and for sustainable general economic development in the Guanzhong Plain. Because of climate change with more frequent and more severe droughts, increasing industrialization and growing household income, the demand for water will rapidly increase which will further increase the need for irrigation water saving. Since it is a major wheat and corn producing region in Northern China which in its turn is China's main 'breadbasket', sustainable agriculture in the Guanzhong Plain is a prerequisite for nationwide food security, as well as for social and political stability. Hence, improving irrigation water use extends far beyond the agricultural sector's sustainable development. Adoption of efficient irrigation techniques is crucial for the realization of this goal.

The Guanzhong Plain is a typical water-scarce region in the North China Plain in terms of water availability, irrigation infrastructure and management, importance of agricultural production, crop structure, urbanization level and percentage of off-farm activities. Hence, the results obtained in this study are likely to hold for similar water-scarce areas in Northern China, though roughly of course. 


\section{References}

Abdulai, A., Glauben, T., Herzfeld, T., Zhou, S., 2005. Water saving technology in Chinese rice production-Evidence from survey data. Accessed December 2015, available at http://ageconsearch.umn.edu/bitstream/24708/1/pp05ab01.pdf.

Abdulai, A., Owusu, V., Bakang, E.A., 2011. Adoption of safer irrigation technologies and cropping patterns: Evidence from Southern Ghana. Ecol. Econ. 70(7), 1415-1423.

Ajzen, I., 1985. From intentions to actions: A theory of planned behaviour. In Kuhl, J. Beckman, J. (Eds.), Action-control: From cognition to behaviour. Heidelberg, Springer, pp. 11-39.

Bewket, W., 2007. Soil and water conservation intervention with conventional technologies in northwestern highlands of Ethiopia: Acceptance and adoption by farmers. Land Use Policy 24, 404-416.

Blanke, A., Rozelle, S., Lohmar, B., Wang, J., Huang, J., 2007. Water saving technology and saving water in China. Agr. Water Manage. 87, 139-150.

Boncinelli, F., Bartolini, F., Casini, L., Brunori, G., 2016. On farm non-agricultural activities: Geographical determinants of diversification and intensification strategy. Lett. Spat. Resour. Sci. forthcoming.

Carey, M.J., Zilberman, D., 2002. A model of investment under uncertainty: Modern irrigation technologies and emerging markets in water. Am. J. Agr. Econ. 84(1), 171-183. Czekaj, T., Henningsen, A., 2013. Panel data nonparametric estimation of production risk and risk preferences: An application to Polish dairy farms. Accessed December 2015, available at http://econpapers.repec.org/paper/foiwpaper/2013_5f6.htm.

De Graaff, J., Kessler, A., Olsen, P., 2010. Farm-level adoption of soil and water conservation measures and policy implications in Europe. Land Use Policy 27, 1-3. 
Deressa, T.T., Hassan, R.M., Ringler, C., 2011. Perception of and adaptation to climate change by farmers in the Nile Basin of Ethiopia. J. Agr. Sci. 149, 23-31.

Dimara, E., Skuras, D., 2003. Adoption of agricultural innovations as a two-stage partial observability process. Agr. Econ. 28, 187-196.

Dinar, A., Yaron. D., 1992. Adoption and abandonment of irrigation technologies. Agr. Econ. 6, 315-332.

Doss, C.R., 2006. Analyzing technology adoption using micro studies: Limitations, challenges, and opportunities for improvement. Agr. Econ. 34, 207-219.

Du, P., Parmeter, C.F., Racine, J.S., 2013. Nonparametric kernel regression with multiple predictors and multiple shape constraints. Stat Sin 23, 1343-1372.

Erwin, C.A., Ervin, D.E., 1982. Factors affecting the use of soil conservation practices: Hypothesis, evidence, and policy implications. Land Econ. 58, 277-292.

Feder, G., Just, R., Zilberman, D., 1985. Adoption of agricultural innovations in developing countries: A survey. Econ. Dev. Cult. Change 33(2), 255-298.

Foster, A.D., Rosenzweig, M.R., 2010. Microeconomics of technology adoption. Annu. Rev. Econ. 2, 395-424.

Foudi, S., Erdlenbruch, K., 2012. The role of irrigation in farmers' risk management strategies in France. Eur. Rev. Agric. Econ. 39(3), 439-457.

Green, G., Sunding, D., Zilberman, D., Parker, D., 1996. Explaining irrigation technology choices: A microparameter approach. Am. J. Agr. Econ. 78, 1064-1072.

Groom, B., Koundouri, P., Nauges, C., Thomas, A., 2008. The story of the moment: risk averse cypriot farmers respond to drought management. Appl. Econ. 40, 315-326.

Habiba, U., Shaw, R., Takeuchi, Y., 2012. Farmer’s perception and adaptation practices to cope with drought: perspectives from Northwestern Bangladesh. Int. J. Disaster Risk Reduction 1, 72-84. 
Just, D.R., Khantachavana, S.V., Just, R.E., 2010. Empirical challenges for risk preferences and production. Annu. Rev. Resour. Econ. 2, 13-31.

Just, R.E., Pope, R.D., 1978. Stochastic specification of production functions and economic implications. J. Econometrics 7, 67-89.

Kato, E., Ringler, C., Yesuf, M., Bryan, E., 2011. Soil and water conservation technologies: a buffer against production risk in the face of climate change? Insights from the Nile Basin in Ethiopia. Agr. Econ. 42, 593-604.

Khan, S., Hanjra, M.A., Mu, J., 2009. Water management and crop production for food security in China: A review. Agr. Water Manage. 96, 349-360.

Knowler, D., Bradshaw, B., 2007. Farmers' adoption of conservation agriculture: a review and synthesis of recent research. Food Policy 32(1), 25-48.

Kumbhakar, S.C., 2002. Specification and estimation of production risk, risk preferences and technical efficiency. Am. J. Agr. Econ. 84, 386-390.

Kumbhakar, S.C., Tsionas, E. G., 2009. Nonparametric estimation of production risk and risk preference functions. In Li, Q., Racine, J.S. (Eds.), Nonparametric Econometric Methods (Advances in Econometrics, Volume 25), Emerald Group Publishing Limited, Bingley, pp. 223-260.

Kumbhakar, S.C., Tsionas, E.G., 2010. Estimation of production risk and risk preference function: a nonparametric approach. Ann. Oper. Res. 176, 369-378.

Li, X., Gan, C., Hu, B., 2011. Accessibility to microcredit by Chinese rural households. J. Asian Econ. 22(3), 235-246.

Liu, E., 2013. Time to change what to sow: Risk preferences and technology adoption decisions of cotton farmers in China. Rev. Econ. Statist. 95(4), 1386-1403.

Liu, E., Huang, J., 2013. Risk preferences and pesticide use by cotton farmers in China. J. Dev. Econ. 103, 202-215. 
Lohmar, B., Wang, J., Rozelle, S., Huang, J., Dawe, D., 2003. China’s agricultural water policy reforms: Increasing investment, resolving conflicts, and revising incentives. Accessed December 2015, available at http://ageconsearch.umn.edu/handle/33643.

Marra, M., Pannell, D.J., Ghadim, A.A., 2003. The economics of risk, uncertainty and learning in the adoption of new agricultural technologies: Where are we on the learning curve? Agr. Syst. 75(2-3), 215-234.

MWR (Ministry of Water resources), 2011. China water resources bulletin 2011. China Water Power Press, Beijing.

MWR (Ministry of Water resources), 2012. China water resources bulletin 2012. China Water Power Press, Beijing.

Paxton, K.W., Mishra, A.K., Chintawar, S., et al., 2011. Intensity of precision agriculture technology adoption by cotton producers. Agr. Resource Econ. Rev. 40(1), 133-144.

Piao, S.L., Ciais, P., Huang, Y. et al. 2010. The impacts of climate change on water resources and agriculture in China. Nature 467, 43-51.

Picazo-Tadeo, A.J., Wall. A., 2011. Production risk, risk aversion and the determination of risk attitudes among Spanish rice producers. Agr. Econ. 42, 451-64.

Sajaia, Z., 2008. Maximum likelihood estimation of a bivariate ordered probit model: Implementation and Monte Carlo simulations. The Stata J. 4(2), 1-18.

Scolobig, A., De Marchi, B., Borga, M., 2012. The missing link between flood risk awareness and preparedness: Findings from case studies in an Alpine Region. Nat. Hazards 63(2), 499-520.

Semgalawe, Z., Folmer, H., 2000. Household adoption behaviour of improved soil conservation: The case of the North Pare and West Usambara Mountains of Tanzania. Land Use Policy 17(4), 321-336. 
Serra, T., Zilberman, D., Gil, J.M., 2008. Differential uncertainties and risk attitudes between conventional and organic producers: the case of Spanish arable crop farmers. Agr. Econ. 39, 219-229.

Shalizi, Z., 2006. Addressing China’s growing water shortages and associated social and environmental Consequences. World Bank, Washington D.C.

Shiferaw, B., Holden, S., 1998. Resource degradation and adoption of land conservation technologies in the Ethiopian highlands: case study in Andit Tid, North Shewa. Agr. Econ. 27 (4), 739-752.

SPBS (Shaanxi Provincial Bureau of Statistics), 2012. Shaanxi Statistical Yearbook 2012. China Statistics Press, Beijing.

Tang, J., Folmer, H., van der Vlist, A.J., Xue, J., 2013a. The impacts of management reform on irrigation water use efficiency in the Guanzhong plain, China. Pap. Reg. Sci. 93(2), 455-475.

Tang, J., Folmer, H., Xue, J., 2015. Technical and allocative efficiency of irrigation water use in the Guanzhong Plain, China. Food Policy 50, 43-52.

Tang, J., Folmer, H., Xue, J., 2013b. Estimation of awareness and perception of water scarcity among farmers in the Guanzhong Plain, China, by means of a structural equation model. J Environ. Manage. 126, 55-62.

Tucker, C.M., Eakin, H., Castellanos, E.J., 2010. Perceptions of risk and adaptation: coffee producers, market shocks, and extreme weather in Central America and Mexico. Global Environ. Chang. 20, 23-32.

von Neumann, J., Morgenstern, O., 1947. Theory of games and economic behavior, 2nd ed. Princeton University Press, Princeton. 
Wachinger, G., Renn, O., Begg, C., Kuhlicke, C. 2013. The risk perception paradoximplications for governance and communication for natural hazards. Risk Anal. 33, 1049-1065.

Wang, H., Liu, C., Zhang, L., 2002. Water-saving agriculture in China: An overview. Adv. Agron. 75, 135-171.

Wang, J., Huang, J., Rozelle, S., Huang, Q., Blanke, A., 2007. Agriculture and groundwater development in Northern China: Trends, institutional responses and policy options. Water Policy 9, 61-74.

Zhang, X., Wang, S., Sun, H., Chen, S., Shao, L., Liu, X., 2013. Contribution of cultivar, fertilizer and fertilizer and weather to yield variation of winter wheat over three decades: a case study in the North China Plain. Eur. J. Agron. 50, 52-59.

Zhou, S., Herzfeld, T., Glauben, T., Zhang, Y., Hu, B., 2008. Factors affecting Chinese farmers’ decisions to adopt a water-saving technology. Can. J. Agr. Econ. 56, 51-61. 
Figure 1 The conceptual adoption model

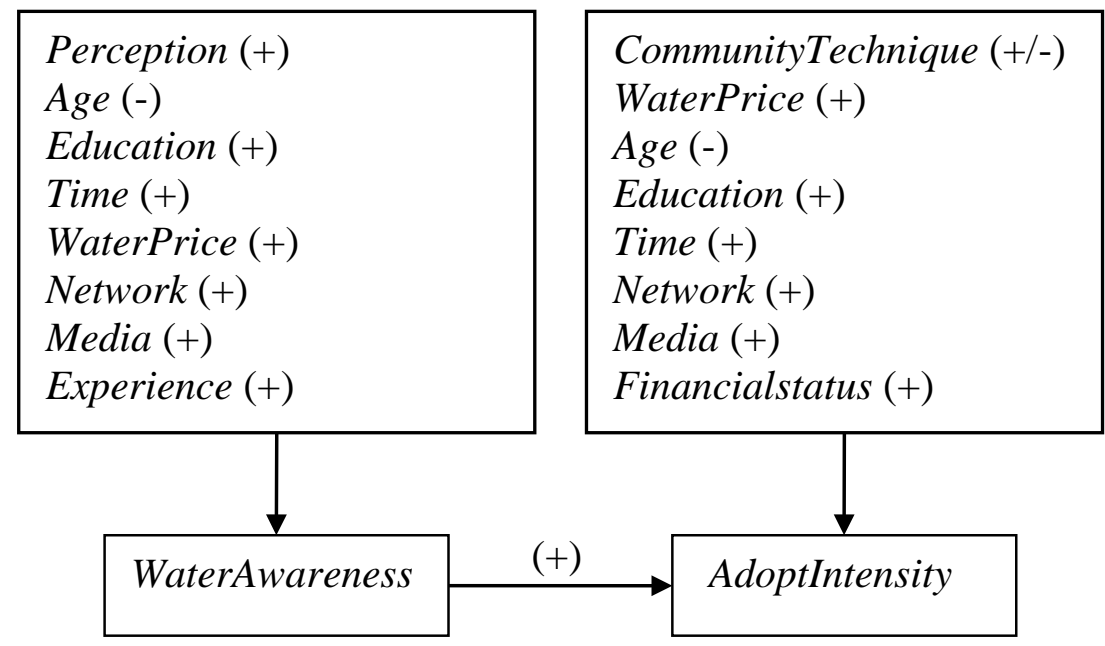

Note: The above system is a recursive system which implies that each sub-model can be estimated separately. Within brackets are expected signs.

Table 1 Descriptive statistics ${ }^{\mathrm{d}}$

\begin{tabular}{llllll}
\hline Variables & Unit of Measurement & Mean & S.D. & Min & Max \\
\hline Output & Yuan/mu & 877.94 & 151.71 & 250 & 1544 \\
Labor & man-days/mu & 2.04 & 1.24 & 0.45 & 7.48 \\
Water & $\mathrm{m}^{3} / \mathrm{mu}$ & 260.02 & 148.41 & 37.5 & 1242 \\
Other inputs & Yuan/mu & 349.55 & 80.47 & 132 & 599 \\
Age & Years & 53.04 & 10.08 & 26 & 77 \\
Education & Years & 6.64 & 1.70 & 0 & 12 \\
Water price $^{\text {Network }}{ }^{\text {a }}$ & Yuan/m & & 0.14 & 0.02 & 1.16 \\
Media $^{\text {a }}$ & & 0.32 & 0.14 & 10 \\
Experience $^{\text {a }}$ & & 6.22 & 1.49 & 4 & 20 \\
FinancialStatus $^{\text {a }}$ & & 8.96 & 2.16 & 4 & 5 \\
AdoptIntensity $^{\text {a }}$ & & 2.73 & 1.48 & 1 & 5 \\
WaterAwareness $^{\text {b }}$ & & 2.16 & 1.24 & 1 & 3 \\
Nmigrants $^{\mathrm{c}}$ & & 1.18 & 0.89 & 0 & 2.43 \\
\hline
\end{tabular}

Notes: ${ }^{a}$ For units of measurement, see Section 2.2. ${ }^{b}$ For unit of measurement, see Tang et al. (2013b). ${ }^{c}$ Nmigrants, i.e. number of migrant workers in the family, is used as an instrumental variable for FinancialStatus. ${ }^{\mathrm{d}}$ Sample size 357. Source: Authors' survey. 
Table 2 Descriptive statistics on adoption of water-saving techniques ${ }^{\mathrm{d}}$

\begin{tabular}{|c|c|c|c|}
\hline Stages of irrigation process & Irrigation techniques & Number of adopters & $(\%)$ \\
\hline \multirow{3}{*}{ Stage I/Community-based ${ }^{\text {a }}$} & \multirow{3}{*}{$\begin{array}{l}\text { Earthern-lined canal } \\
\text { Cement-lined canal } \\
\text { Transportation pipeline }\end{array}$} & 147 & $41 \%$ \\
\hline & & 195 & $55 \%$ \\
\hline & & 15 & $4 \%$ \\
\hline \multirow{4}{*}{ Stage II } & Flood & 68 & $19 \%$ \\
\hline & & 13 & $4 \%$ \\
\hline & Furrow & 280 & $78 \%$ \\
\hline & Spray pipe & 18 & $5 \%$ \\
\hline \multirow{3}{*}{ Stage III } & \multirow{3}{*}{$\begin{array}{l}\text { Mulching } \\
\text { Drought-resistant variety } \\
\text { Fertigation }\end{array}$} & \multirow{2}{*}{$\begin{array}{l}34 \\
20\end{array}$} & $10 \%$ \\
\hline & & & $6 \%$ \\
\hline & & 39 & $11 \%$ \\
\hline AdoptIntensity ${ }^{\mathrm{b}}$ & $\begin{array}{c}\text { Non-adoption } \\
\text { (0) }\end{array}$ & $\begin{array}{l}\text { Medium-level } \\
\text { (2) }\end{array}$ & $\begin{array}{l}\text { High-level } \\
\text { (3) }\end{array}$ \\
\hline Number of farmers & $62^{c}$ & 26 & 51 \\
\hline
\end{tabular}

Notes: ${ }^{\text {a }}$ The adoption of community-based techniques is not used to define AdoptIntensity because adoption of community-based techniques is a collective (group) behavior. We only focus on the farm-based irrigation techniques because their adoption is decided by individual farmers, rather than by a group of farmers. ${ }^{\text {b }}$ AdoptIntensity takes the value 0 in the case of non-adoption (flood irrigation); 1 if a farmer has adopted at least one of the low-level techniques and no medium or high level techniques; 2 if at least one of the medium-level techniques has been adopted, but no high-level techniques; 3 if at least one of the high level techniques has been adopted. ${ }^{\mathrm{c}}$ The number of farmers $(\mathrm{n}=62)$ whose AdoptIntensity are 0 is smaller than the number of flood irrigators ( $\mathrm{n}=68$ ) because 6 of them also used a higher level farm-based technique and were classified accordingly. In a similar vein, the score of AdoptIntensity 3 is 51 and not 20+39 because 8 farmers use both techniques. ${ }^{\mathrm{d}}$ Sample size 357. Source: Author’s survey.

Table 3 Measurement model (standardized coefficients)

\begin{tabular}{lllll}
\hline Latent variables & Indicators & Coefficients & S.E. & $R^{2}$ \\
\hline \multirow{3}{*}{ WaterAwareness } & Aware1 & 0.565 & --- & 0.32 \\
& Aware2 & $0.589^{* * *}$ & 0.073 & 0.35 \\
& Aware3 & $0.145^{* *}$ & 0.060 & 0.02 \\
\multirow{2}{*}{ Perception } & Percep1 & 0.842 & --- & 0.71 \\
& Percep2 & $0.503^{* * *}$ & 0.055 & 0.25 \\
& Percep3 & $0.283^{* * *}$ & 0.056 & 0.08 \\
\hline
\end{tabular}

Notes. (1) ${ }^{* * *}: \mathrm{p}^{<.01},{ }^{* *}: \mathrm{p}<0.05$. (2) The coefficients of Aware1 and Percep1 are fixed to assign measurement scales to the latent variables WaterAwareness and Perception to render the structural equation model with latent variables (SEM) identified (see Tang et al., 2013b). 
Table 4 Structural WaterAwareness-Perception model (standardized coefficients)

\begin{tabular}{lllll}
\hline \multirow{2}{*}{ Variables } & \multicolumn{2}{c}{ WaterAwareness } & \multicolumn{2}{c}{ Perception } \\
& Coefficients & S.E. & --- & Coefficients \\
\hline Perception & $0.706^{* * *}$ & 0.089 & 0.108 & --- \\
WaterAwareness & --- & --- & -- & 0.225 \\
Age & $-0.127^{* *}$ & 0.064 & --- & -- \\
Education & -0.062 & 0.060 & 0.046 & -- \\
Time & $0.141^{* *}$ & 0.065 & --- & 0.054 \\
Media & -0.023 & 0.059 & 0.034 & -- \\
WaterPrice & --- & ---- & 0.037 & 0.039 \\
Network & $0.350^{* * *}$ & 0.069 & $0.744^{* * *}$ & 0.103 \\
Experience & --- & --- & 0.70 & \\
$R^{2}$ & 0.80 & & &
\end{tabular}

Table 5 Simultaneously estimated bivariate Probit model of AdoptIntensity and FinancialStatus

\begin{tabular}{|c|c|c|c|c|}
\hline Variables & & model & & model \\
\hline Dependent variable: $A d$ & & & & \\
\hline Explanatory Variables & Estimates & S.E. & Estimates & S.E. \\
\hline Age & -0.002 & 0.010 & & \\
\hline Education & 0.027 & 0.037 & & \\
\hline Time & 0.043 & 0.041 & & \\
\hline WaterPrice & -0.409 & 0.469 & & \\
\hline Network & 0.025 & 0.070 & & \\
\hline Media & 0.018 & 0.034 & & \\
\hline WaterAwareness & 0.119 & 0.127 & $0.154 * *$ & 0.067 \\
\hline CommunityTechnique & $-0.244^{*}$ & 0.133 & $-0.246^{*}$ & 0.126 \\
\hline FinancialStatus & 0.185 & 0.241 & $0.258 *$ & 0.150 \\
\hline Dependent variable: Fi & & & & \\
\hline Age & $-0.020 * *$ & 0.009 & $-0.018 * *$ & 0.008 \\
\hline Education & -0.015 & 0.036 & & \\
\hline Time & -0.022 & 0.041 & & \\
\hline WaterPrice & 0.679 & 0.421 & & \\
\hline Network & $0.182 * * *$ & 0.052 & $0.180 * * *$ & 0.051 \\
\hline Media & $0.074 * * *$ & 0.027 & $0.075^{* * *}$ & 0.027 \\
\hline WaterAwareness & $-0.286 * * *$ & 0.110 & $-0.269 * *$ & 0.106 \\
\hline CommunityTechnique & 0.131 & 0.120 & 0.130 & 0.119 \\
\hline Nmigrants & $0.116^{* *}$ & 0.053 & $0.118^{* *}$ & 0.050 \\
\hline Log-likelihood & -832.21 & & 835.08 & \\
\hline
\end{tabular}

Notes: ${ }^{*}: \mathrm{p}<.10,{ }^{* *}: \mathrm{p}<.05,{ }^{* * *}: \mathrm{p}<.01$. 
Table 6 Marginal effects on the probabilities of adoption of farm-based techniques for the Final model in Table 5.

\begin{tabular}{lllll}
\hline Variables & AdoptIntensity=0 & AdoptIntensity=1 & AdoptIntensity=2 & AdoptIntensity=3 \\
WaterAwareness & $-0.037^{* * *}$ & -0.009 & $0.009^{* * *}$ & $0.037^{* * *}$ \\
& $(0.012)$ & $(0.022)$ & $(0.003)$ & $(0.012)$ \\
CommunityTechnique & $0.069^{* * *}$ & -0.006 & $-0.015^{* * *}$ & $-0.048^{* * *}$ \\
& $(0.019)$ & $(0.037)$ & $(0.003)$ & $(0.019)$ \\
FinancialStatus & $-0.059^{* * *}$ & -0.021 & $0.015^{* * *}$ & $0.065^{* * *}$ \\
& $(0.020)$ & $(0.035)$ & $(0.005)$ & $(0.019)$ \\
\hline
\end{tabular}

Notes. (1) The coefficients denote changes of probabilities of AdoptIntensity due to unit changes of the explanatory variables. (2) Standard errors in brackets. (3) ${ }^{*}: \mathrm{p}<.10,{ }^{* *}: \mathrm{p}<.05,{ }^{* * *}: \mathrm{p}<.01$.

Table 7 Marginal effects of inputs and irrigation techniques on the mean production function $f(X, A I)$ and the risk function $g(X, A I)$

\begin{tabular}{|c|c|c|c|c|c|c|}
\hline$f(X, A I)$ & Mean & S.D. & Min. & Max. & \multicolumn{2}{|c|}{ 95\% Confidence Interval } \\
\hline Labor & 9.739 & 13.650 & 0.001 & 70.449 & 8.318 & 11.159 \\
\hline Water & 0.056 & 0.045 & 0.001 & 0.264 & 0.051 & 0.060 \\
\hline Other inputs & 0.304 & 0.403 & 0.001 & 2.733 & 0.262 & 0.346 \\
\hline CommunityTechnique & 43.765 & 29.191 & -39.195 & 133.270 & 40.727 & 46.803 \\
\hline AdoptIntensity & 3.819 & 32.321 & -49.695 & 98.186 & 0.455 & 7.183 \\
\hline \multicolumn{7}{|l|}{$g(X, A I)$} \\
\hline Labor & 10.981 & 4.002 & -2.675 & 16.702 & 10.565 & 11.398 \\
\hline Water & -0.007 & 0.049 & -0.215 & 0.107 & -0.013 & -0.002 \\
\hline Other inputs & 0.127 & 0.149 & -0.503 & 0.317 & 0.112 & 0.143 \\
\hline CommunityTechnique & -5.404 & 8.354 & -23.960 & 54.501 & -6.273 & -4.534 \\
\hline AdoptIntensity & -3.263 & 3.741 & -17.110 & 6.969 & -3.653 & -2.874 \\
\hline
\end{tabular}


Figure 2 Distribution of the marginal effects on output of CommunityTechnique (a) and AdoptIntensity (b)
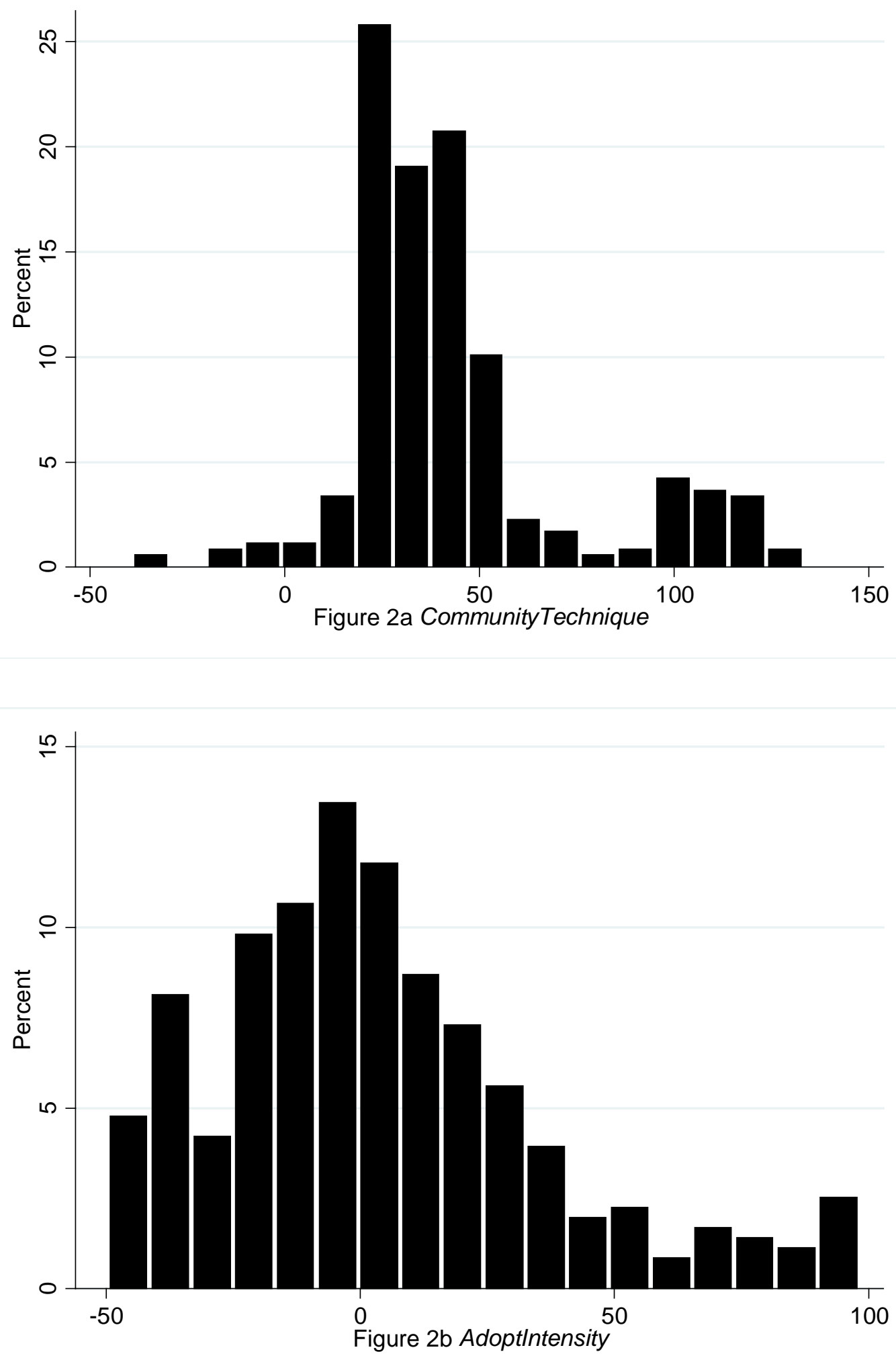
Figure 3 Distribution of marginal effects on production risk of Cement-lined canals or Transportation pipelines (a) and AdoptIntensity (b)
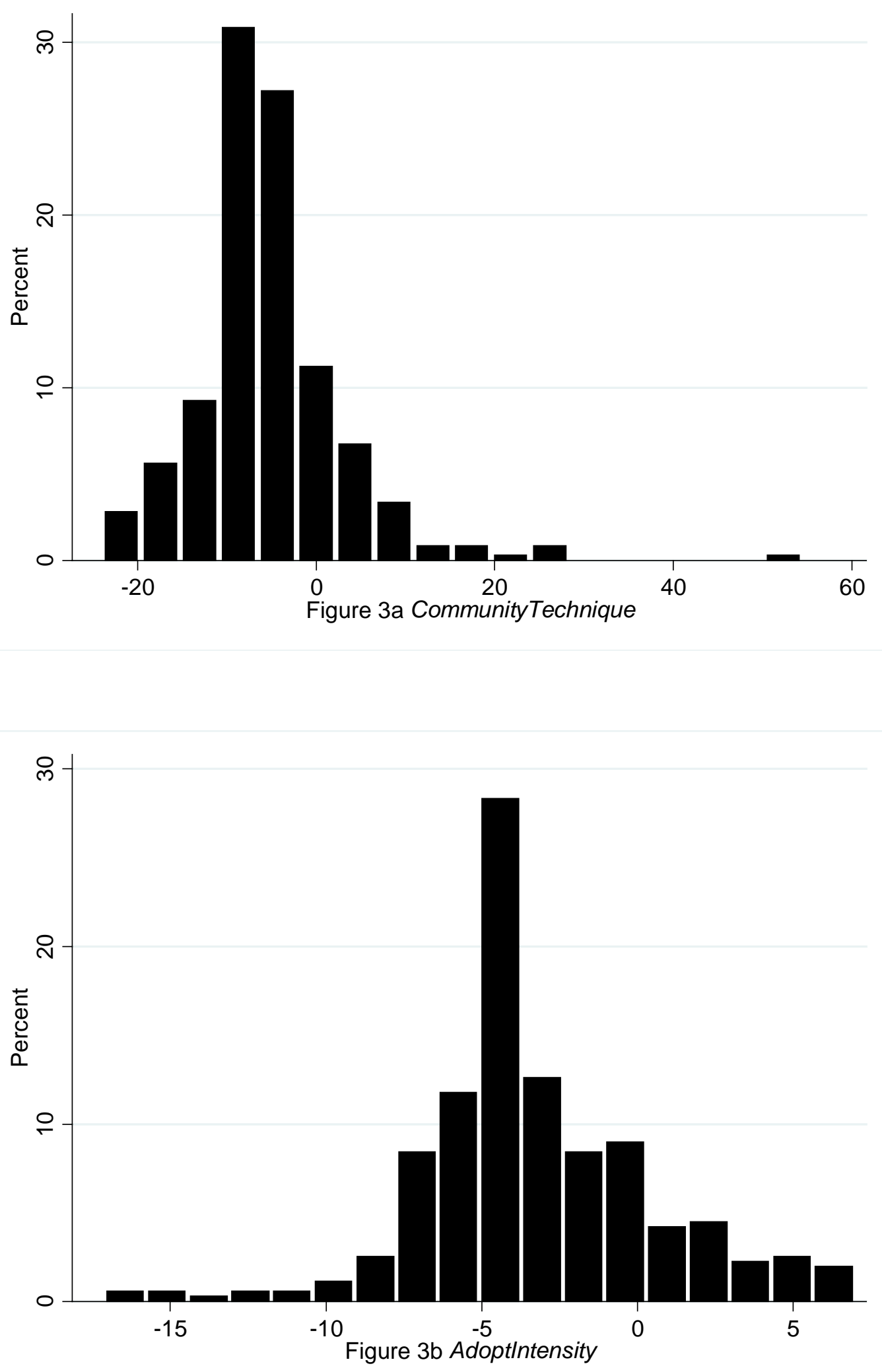
